\title{
E-Contents for Technological Literacy in a Pre-College Program
}

\author{
Yukari Kato \\ Tokyo University of Agriculture and Technology, Japan
}

\begin{abstract}
This study provided attractive course materials for technological literacy education for a wider audience, including first-year students, high school students, and foreign students in pre-college courses. This prototype eLearning system is designed to engage a wider range of engineering faculty students paired up with Japanese language teachers to develop an e-Learning system, creating four modules that include video lectures, auto glossary for technical terms, reading materials with narration, and two types of comprehension activities. Evaluation results indicate that a multimedia eLearning environment is effective and has the potential to better prepare students for engineering education, especially for advanced learners of Japanese in pre-engineering courses.
\end{abstract}

Keywords: Web-Based Training, Japanese Language Education, Literacy Education, Wider Audience, First-Year Program

\section{INTRODUCTION}

With the advent of technology, multimedia e-Learning systems are becoming ubiquitous for language learning on university campuses. Using these systems, the language learning process may be made more flexible, rich and individualized. However, in order to be successful, systems must be adapted to and take into account both learners' mental processes and academic requirements in their specialized fields.

There are questions about whether language teachers who are working in isolation can design appropriate courses for a wide variety of learners and their various needs, interests, and academic disciplines. Fukao (1994), from the viewpoint of Japanese language teachers, discusses the difficulties of selecting adequate materials and designing language courses for intermediate to advanced students who must be able to read academic articles. The first issue is that language teachers do not have enough specific knowledge to be able to cover all specialized fields. The second issue is that

Please use the following format when citing this chapter:

Kato, Y., 2009, in IFIP International Federation for Information Processing, Volume 292; Evolution of Information Technology in Educational Management; Eds. Tatnall, A., Visscher, A., Finegan, A., O'Mahony, C., (Boston: Springer), pp. 43-56. 
foreign students are apt to lose interest in reading materials that are not closely related to their specialized field. This may be due to a lack of interest and knowledge in "teaching advanced skills" in Japanese language education. In other words, Japanese language programs for engineers and scientists have been struggling to meet student demand for advanced language courses due to a lack of adequate resources in funding and personnel.

A possible solution for the above difficulties is to base Japanese language curricula on literacy education for a wider audience, including functions that support both language and specialized learning. In fact, Yamamoto (1995) indicated in her report on a Japanese summer course at Massachusetts Institute of Technology (MIT) that cooperation between Japanese language teachers and the science and engineering faculty enhanced students' understanding of Japanese academic articles. This kind of teaching strategy holds promise for the development of an adequate curriculum for advanced Japanese learners in specialized fields. In another example, in China, Japanese language teachers and academic faculty have cooperated to support Chinese students' acquisition of necessary college skills prior to their study at Japanese universities (Kaji 1983)(Tsujii 1983). In contrast, in Japan, only a few attempts have been made so far at forging cooperation between language educators and researchers in specialized fields (Konishi 1983).

\subsection{Japanese Language Courses for a Wider Audience}

The question is: what and how do we teach to a wider audience? The wider audience is not limited to non-engineering students (Rover 2006). It encompasses high school students, foreign students in pre-college courses, and teachers in K-12 schools, all of whom are more diverse in their background and interests. To answer the question, we might consider what is taught to first-year students in technical colleges and universities and to the next generation of pre-engineering students. Additionally, given the content, how do these audiences learn about engineering? Interestingly, there are relatively few textbooks or trade books published on this topic.

To solve these types of problems, the e-Learning project for the Advanced Japanese Language Course was developed at Tokyo University of Agriculture and Technology in Tokyo, Japan though collaborations among professors from the College of Engineering and Agriculture and Japanese language teachers. The materials from the e-Learning project have already been published as a trade book to introduce to the next generation the specialized research topics in technology. Through cooperation between language teachers and professionals, e-Learning content has been under development since 2006.

This project was also motivated in part by a desire to develop new technological literacy e-Learning content for a wider audience. Shin \& Wastel (2001) argue that the design of CALL (Computer Assisted Language Learning) should be 1) underpinned by a solid educational model, and 2) 
informed by a rigorous engineering approach ensuring that the design addressees the educational requirements of its potential users. It is significant that user goals are mentioned less frequently in CALL literature than user characteristics, needs, profiles and so forth (Colpaert 2006).

Watts (1997) mentioned that the goals of language education might be seen in terms of improved language skills such as increased proficiency in speaking and writing or acquisition of particular knowledge sets, or in general areas such as gaining a better appreciation of another culture.

In order to accomplish these requirements, this project aimed to develop e-Learning content that integrates linguistic skill with an emphasis on reading comprehension skills (Kato et al. 2002) and focuses on technological literacy for a wider audience. This paper is organized as follows: Section 2 describes the e-Learning courseware designs, which were implemented by combining four different strategic learning modules on an LMS Server (moodle, http://moodle.elp.tuat.ac.jp/moodle/login/index.php). Section 3 outlines the survey used to investigate the evaluations of 22 firstyear engineering students and 21 foreign students in a pre-engineering course. Section 4 examines the results of the survey and discusses the design for system development. Finally, the paper closes with conclusions and intentions for future work.

\section{E-LEARNING CONTENT DEVELOPMENT}

This e-Learning development aimed to integrate Japanese language education with an emphasis on technological literacy in engineering education. It has been implemented with cooperation between Japanese language teachers and professionals in science and engineering.

Course design was decided by taking the following factors into account:

1) Flexible learning environment for learners' diversity. Technology would provide learners with greater opportunities for exposure to scientific documents, lectures and task-based activities, with the possibility of many hours of independent work at their own pace.

2) Sharing knowledge for technical literacy education. Content was developed through cooperation between Japanese language teachers and professionals in specialized fields. Through this collaborative work, knowledge for designing technical literacy curricula was discussed and shared.

\subsection{Hybrid Online Course for Technological Literacy}

The complete e-Learning content for technological literacy is made up of six modules implemented in the moodle platform (http://moodle.elp.tuat. ac.jp/moodle/login/index.php): (a) technical text reading with narration, (b) auto glossary of technical terms, (c) video clips with transcription, (d) comprehension tasks for streaming lecture, (e) comprehension tasks for 
reading material, and (f) comprehension tasks for graphical information, as shown in Fig. 1.

Through Modules (a) and (b), as shown in Fig. 2 and Fig. 3, students learn and understand meanings and pronunciations of technical terms in documents. In particular, narration is helpful in understanding how to pronounce words that are not used frequently in daily life. Complex sentence structures and Kanji characters that comprise a large portion of technical writing may cause problems for language learners' comprehension process in lower order decoding. Confirming sounds and meanings in technical documents is valuable for teaching advanced Japanese language (Yamamoto 1995).

Module (a) technical reading with narration (Fig 2) and Module (b) auto glossary of technical terms (Fig. 3) were designed to promote better understanding of linguistic features in academic texts.

These modules mainly focused on identifying and recognizing word meanings and grammatical forms.

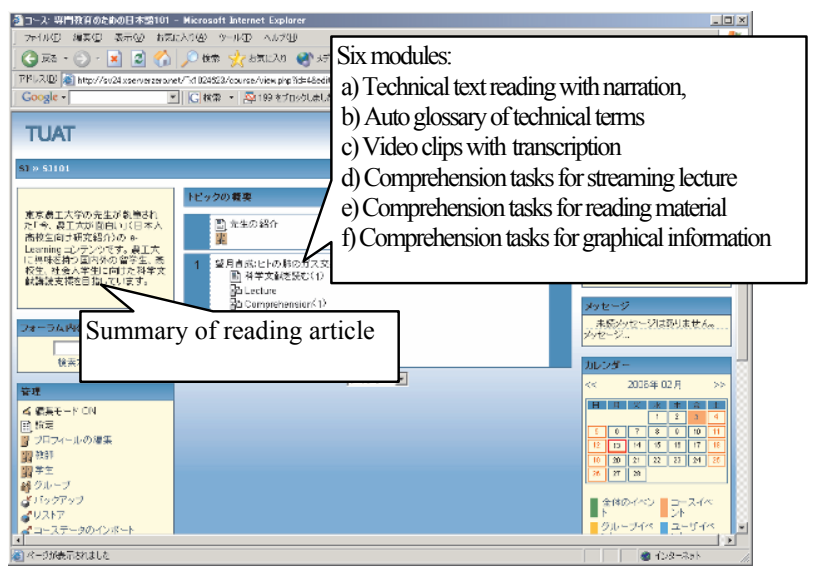

Figure 1: Top page of e-Learning system

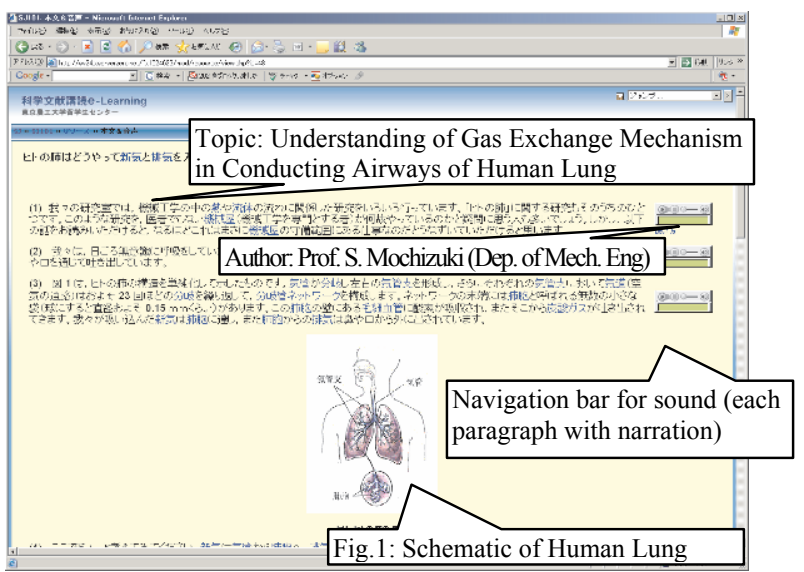

Figure 2: Technical reading with narration 


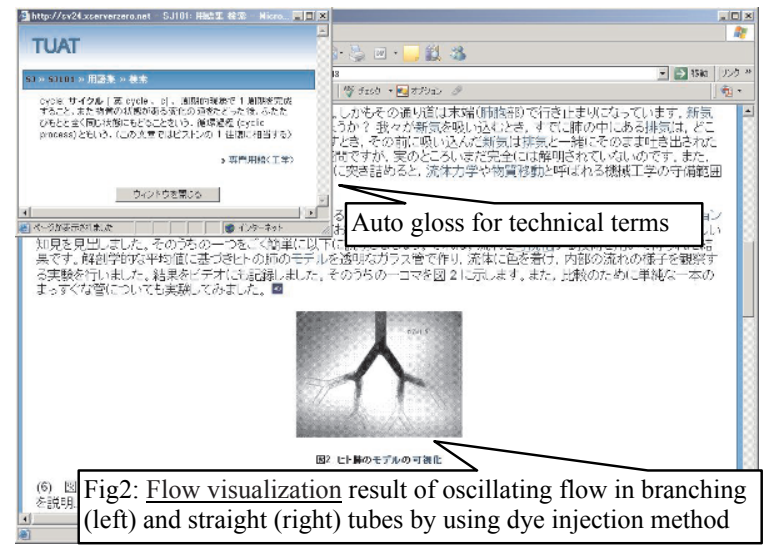

Figure 3: Auto glossary of technical terms

Module (c), as shown in Fig. 4, builds in video clips related to the main ideas of documents that were shown in Module (a). In order to promote listening comprehension in international students and beginners in the engineering department, video clips are linked to texts that describe the main ideas of lectures. The content of lectures is adjusted to the level of an introductory course for high school students and the first year students.

Module (d) includes lecture comprehension tasks that facilitate content understanding and language skills that lay the foundation of engineering education.

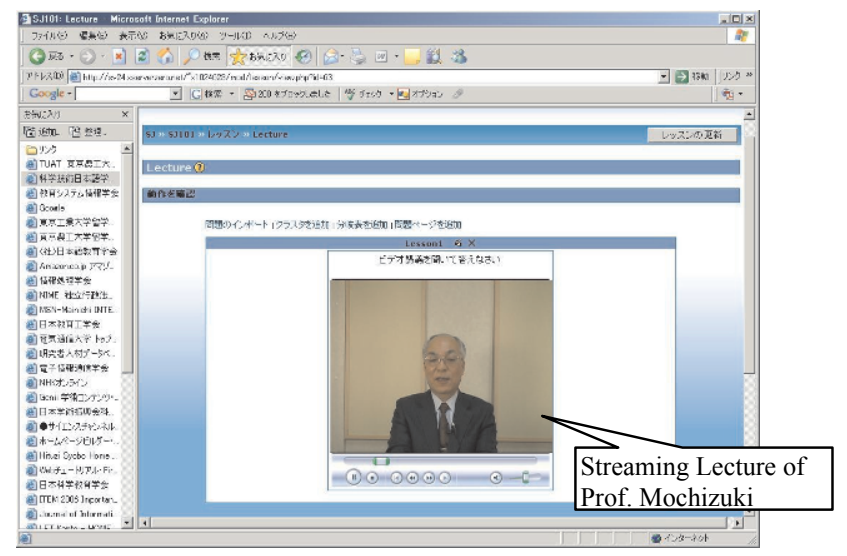

Figure 4: Video clips with transcription

Modules (e) and (f) were comprehension tasks for the reading material. Graphical information and video clips are embedded in textual documents as shown in Fig. 5. In our courseware, a total of six strategic modules, detailed above, were developed. 


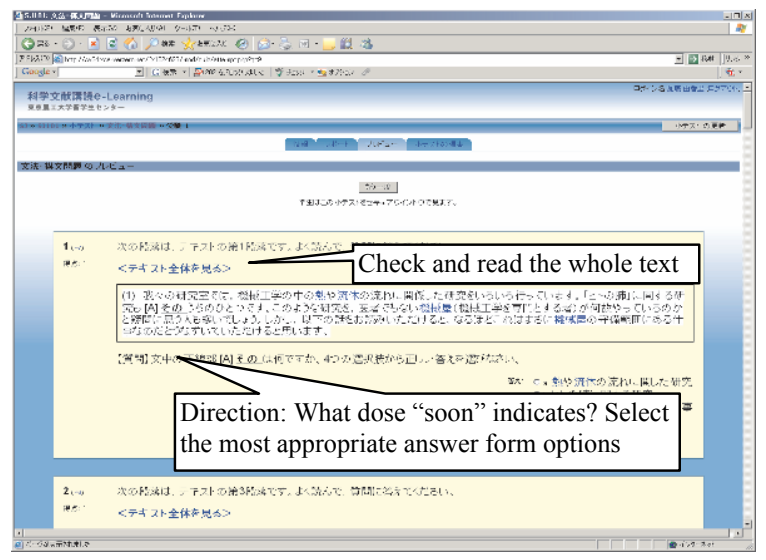

Figure 5: Comprehension tasks for the reading material

\section{EVALUATION SURVEY FOR MULTIMEDIA COURSEWARE}

This research aimed to consider specific practice guidelines that are research-based and implemented in educational settings (Foshay, Silber \& Stelnicki 2003). An important criterion of success for e-Learning in language classrooms is whether it is acceptable to learners. However, few research studies have investigated learners' use of computerized reading modules (Ercetin 2003). Previous research suggested that foreign students show favourable attitudes toward new tasks and explanation with graphics in eLearning reading content. Conversely, Japanese language teachers showed negative attitudes toward ordinary language tasks. During the post-survey debriefing, the teachers were particularly pleased with explicitness and validity of instruction (Kato 2005). For example, some teachers reported that multilingual dictionaries and multimedia tools were desirable when dealing with students of various language levels. In order to understand the strengths and limitations of this survey and to design and develop language-learning systems efficiently, systematic and consistent evaluation by both learners and teachers is necessary. Therefore, we developed a new e-Learning system (moodle: http://moodle.elp.tuat.ac.jp/moodle/login/index.php): that includes more multimedia resources and language tasks for a wider audience (Kato \& Akiyama 2006)(Kato 2006).

We believe that the multimedia-based approach is effective and has the potential to better prepare students for academic life at colleges and universities.

\subsection{Objectives}

The purpose of the survey presented here was to elicit students' perceptions of how well the course was designed by language learning/teaching framework and their reactions to various methods used in multimedia 
e-Learning. The purpose of this survey was to systematically explore both advanced Japanese language learners' and native Japanese students' interaction with multimedia modules designed to promote understanding of academic writing and to support technological literacy in engineering. Additionally, by collecting data from non-engineering students, we were able to consider ways to teach technological literacy to a wider audience.

The survey investigated the following two questions:

(a) Are there any differences between engineering and non-engineering majors with regard to their preference for multimedia e-Learning?

(b) Are there any differences between foreign and native Japanese students in engineering with regard to their preference for multimedia e-Learning?

\subsection{Procedure}

\subsubsection{Subjects}

The research subjects were 43 native and foreign students studying in public universities in Japan; 34 students majoring in engineering, including 22 advanced learners of Japanese and 12 native Japanese students, and 9 non-engineering native Japanese students. Twenty-one students were native Japanese students, including 7 first-year engineering majors. All advanced learners of Japanese were from Kanji-using countries in Asia: China and South Korea. These students had already received 1-2 years of formal instruction and had passed the first (highest) or second level of the Japanese Proficiency Test.

\subsubsection{Questionnaires and Data Collection Procedures}

One of the most attractive features of e-Learning is that it is capable of allowing both the instructors and the learners to customize instruction and learning according to their needs (Itoh \& Hannon 2002). Previous surveys (Nagata 1996)(Nagata 1998) and interviews (Kato 2005) point to the fact that today's students and teachers require a more interactive, media-rich learning environment. This student survey was used to capture students' reaction to various instructional methods used in an e-Learning system. The survey items targeted students' reaction to various modules implemented to teach understanding of academic writing and to support technological literacy in engineering. These survey items provide a link between students' perceptions of the implemented modules and our anticipated benefits of the multimedia-based methods.

\subsubsection{Procedures of Data Collection}

The same questionnaire was used for both foreign students and advanced learners of Japanese. Individual questions were designed to investigate 
users' subjective preference toward e-Learning systems (function, relevance, achievement, and motivation) in comparison to previous research (Kato 2005), (Obayashi at al. 2002) (Dansuwan et al. 2001)(Suzuki 2002).

Subjects individually used web-based courseware on the Learning Management System (LMS; http://moodle.elp.tuat.ac.jp/moodle/login/index. php). Each subject used four modules that include video lectures, auto glossary of technical terms, reading materials with narration, and two types of comprehension activities, as mentioned in Section 2.1.

After using the e-Learning courseware for one hour, students were asked to read the 29 questionnaire items and indicate their reaction by choosing a number from 1 (disagree) to 4 (strongly agree).

\subsubsection{Factor Analysis}

We conducted item analysis to investigate the discriminative power of 29 questions. Then, 29 items were submitted to factor analysis by using principal component analysis and varimax rotation was conducted. Five items that loaded at less than .54 were excluded: Items $3,11,12,13$ and 14 . Five complex items for multiple-loaded factors were also deleted: Items 1, 10, 18, 24, 25.

Table 1 shows the 19 items loaded by each factor. The cumulative variance of the four factors was extracted $51.56 \%$.

\section{RESULTS}

The pattern matrix for loading greater than .54 as a criterion of factor salience appears in Table 1 (next page).

The first factor included nine items that loaded on $20.47 \%$ of the variance.

We labelled this factor "Positive reaction to e-Learning content.

Representative items are Item 16: "The number of auto glosses is adequate," Item 29: "Studying e-Learning content is fun," and Item 28: "I would like to use other e-Learning content even if it is not in my field."

Factor 2 consisted of four items that loaded on $11.99 \%$ of the variance. This factor was labelled "Effectiveness of Auto Glossary" and included Item 21: "I can answer lecture listening comprehension tasks by use of auto glosses" and Item 23: "I can answer technical reading comprehension tasks by use of auto glosses." This factor seems to evaluate the function of auto glossary in Module (b) with regard to comprehension tasks (lecture listening and technical reading comprehension tasks).

Three items loading on the third factor accounted for $10.30 \%$ of the variance. Examples include Item 8: "Video clips have high-quality sounds" and Item 4: "Lecture listening comprehension tasks are related to the topics of video clips." This factor concerns "Positive Perception of Multimedia Effects," especially quality of sounds in video clips and narrations. 
There were three items included in Factor 4, which was labelled "Positive Perception of Technical Reading with Narrations." One item, Item 22: "Text comprehension tasks are related to practice in the technical reading with narration module," showed users' perceived effectiveness for reading tasks in combination with narration.

Table 1: Items Arranged According to Factor

\begin{tabular}{|c|c|c|c|c|c|}
\hline \multirow{2}{*}{\multicolumn{2}{|c|}{ Items }} & \multicolumn{4}{|c|}{ Factor Loadings } \\
\hline & & \multirow{2}{*}{$\begin{array}{l}\text { Factor 1 } \\
0.911 \\
\end{array}$} & \multirow{2}{*}{\begin{tabular}{|l|} 
Factor 2 \\
0.112 \\
\end{tabular}} & \multirow{2}{*}{$\begin{array}{l}\text { Factor 3 } \\
0.065\end{array}$} & \multirow{2}{*}{$\begin{array}{l}\text { Factor } 4 \\
0.034\end{array}$} \\
\hline Q16 & The number of auto glosses is adequate & & & & \\
\hline Q29 & Studying e-Learning content is fun & 0.863 & -0.111 & 0.404 & 0.136 \\
\hline Q15 & $\begin{array}{l}\text { The content of auto glosses are easy } \\
\text { to understand }\end{array}$ & 0.821 & 0.408 & -0.167 & 0.009 \\
\hline Q2 & $\begin{array}{l}\text { The content of text in technical } \\
\text { reading with narration module are } \\
\text { easy to understand }\end{array}$ & 0.806 & 0.143 & -0.214 & -0.009 \\
\hline Q26 & $\begin{array}{l}\text { I would like to take courses at TUAT } \\
\text { after I study e-Learning content }\end{array}$ & 0.770 & 0.165 & -0.156 & 0.256 \\
\hline Q28 & $\begin{array}{l}\text { I would like to use other e-Learning } \\
\text { content even if it is not in my field. }\end{array}$ & 0.747 & 0.031 & 0.378 & -0.145 \\
\hline Q27 & $\begin{array}{l}\text { I would like to use more varied e- } \\
\text { Learning content }\end{array}$ & 0.746 & -0.005 & 0.533 & -0.168 \\
\hline Q9 & $\begin{array}{l}\text { Video clip modules are easy to access } \\
\text { and watch }\end{array}$ & 0.638 & -0.283 & -0.070 & 0.229 \\
\hline Q17 & More auto glosses are desirable & 0.577 & -0.051 & -0.674 & -0.096 \\
\hline Q21 & $\begin{array}{l}\text { I can answer lecture comprehension } \\
\text { tasks by use of auto glosses }\end{array}$ & 0.051 & 0.935 & -0.032 & -0.171 \\
\hline Q19 & $\begin{array}{l}\text { More plain explanations and } \\
\text { descriptions of auto glosses are } \\
\text { desirable }\end{array}$ & -0.160 & 0.891 & -0.001 & -0.014 \\
\hline Q23 & $\begin{array}{l}\text { I can answer technical reading } \\
\text { comprehension tasks by use of auto } \\
\text { glosses }\end{array}$ & 0.189 & 0.837 & 0.111 & -0.038 \\
\hline Q7 & $\begin{array}{l}\text { Auto glosses are helpful to practice } \\
\text { the technical reading with narration } \\
\text { module }\end{array}$ & 0.388 & 0.731 & 0.023 & -0.048 \\
\hline Q8 & Video clips have high-quality sounds & -0.052 & 0.071 & 0.785 & -0.297 \\
\hline Q4 & $\begin{array}{l}\text { Narrations with technical reading } \\
\text { have high-quality sounds }\end{array}$ & -0.051 & 0.148 & 0.671 & 0.157 \\
\hline Q20 & $\begin{array}{l}\text { Lecture listening comprehension tasks } \\
\text { are related to the topics of video clips }\end{array}$ & 0.111 & -0.279 & 0.624 & 0.357 \\
\hline Q22 & $\begin{array}{l}\text { Practice in the technical reading with } \\
\text { narration module is related to text } \\
\text { comprehension tasks }\end{array}$ & 0.254 & -.221 & -0.076 & 0.833 \\
\hline Q5 & $\begin{array}{l}\text { The sounds are helpful to study } \\
\text { technical reading with narration } \\
\text { module }\end{array}$ & -0.285 & 0.292 & 0.453 & 0.662 \\
\hline Q6 & $\begin{array}{l}\text { The sounds are helpful to continue } \\
\text { studying technical reading with } \\
\text { narration module }\end{array}$ & 0.461 & 0.090 & 0.389 & 0.543 \\
\hline & Rotation Sums of Squared Loadings: & 5.937 & 3.478 & 2.988 & 2.548 \\
\hline & Contribution rate $(\%)$ & 20.47 & 11.99 & 10.30 & 8.79 \\
\hline
\end{tabular}




\subsection{Differences between Foreign and Native Japanese Students}

To investigate the preferences of both foreign students and native Japanese students (including engineering and non- engineering majors) in using eLearning courseware, we compared means and standard deviations on data for the four factors (Positive reaction to e-Learning content, Effectiveness of Auto Glossary, Positive Perception of Multimedia Effects, Positive Perception of Technical Reading with Narrations). Means and standard deviations for the four factors are shown in Table 2 and Fig. 6.

Concerning the first research question, "Are there any differences between engineering and non-engineering majors with regard to their preference for multimedia e-Learning?" we conducted a t-test on data for four factors.

Table 2: Average Scores and Standard Deviation of Native Japanese Students

\begin{tabular}{llcccc}
\hline & Numbers & Factor 1 & Factor 2 & Factor 3 & Factor 4 \\
\hline $\begin{array}{l}\text { Native Japanese } \\
\text { (Engineering) }\end{array}$ & $\mathrm{N}=12$ & 2.63 & 3.00 & 3.08 & 2.60 \\
\hline Native Japanese & $\mathrm{N}=9$ & $(0.64)$ & $(0.92)$ & $(0.71)$ & $(0.73)$ \\
(Non-Engineering) & & $(0.56)$ & $(0.46)$ & $(0.62)$ & $(0.58)$ \\
\hline$T$ & & 0.57 & 1.51 & 0.81 & 0.09 \\
\hline
\end{tabular}

Table 3: Average Scores and Standard Deviation of Engineering Students

\begin{tabular}{lccccc}
\hline & Numbers & Factor 1 & Factor 2 & Factor 3 & Factor 4 \\
\hline $\begin{array}{l}\text { Native Japanese } \\
\text { (Engineering) }\end{array}$ & $\mathrm{N}=12$ & 2.63 & 3.00 & 3.08 & 2.60 \\
\hline $\begin{array}{l}\text { Foreign Students } \\
\text { (Engineering) }\end{array}$ & $\mathrm{N}=22$ & 3.49 & 3.26 & 2.91 & 3.15 \\
\hline$T$ & & $(0.53)$ & $(0.72)$ & $(0.95)$ & $(0.66)$ \\
\hline
\end{tabular}

Factor 1: Positive Reaction to e-Learning Content, Factor 2: Effectiveness of Auto Glossary, Factor 3: Positive Perception of Multimedia Effects, Factor 4: Positive Perception of Reading with Narration.

$* * p<0.01, \dagger p<0.05$

Concerning the second research question, "Are there any differences between foreign and native Japanese students in engineering with regard to their preference for multimedia e-Learning?" we also conducted a t-test on data for four factors, as shown in Table 3 and Fig. 6.

There was no significant difference between foreign students and native Japanese students with regard to Factor 2 (Effectiveness of Auto Glossary) and Factor 3 (Positive Perception of Multimedia Effects).

On the other hand, in Factor 1, the mean for foreign students was significantly higher than that of native Japanese students majoring in engineering, which indicates that foreign students more positively evaluated "Content Effectiveness" of e-Learning courseware than native Japanese students $(\mathrm{t}(32)=4.33, \mathrm{p}<0.01)$. Likewise, there was a slight difference between 
foreign students and native Japanese students for Factor 4, which indicates that foreign students prefer the function of "Reading with Narration" more than Japanese students do ( $\mathrm{t}(32)=1.87, .0 .05<\mathrm{p}<0.10)$.

However, with regard to all four factors there was no significant difference between engineering and non-engineering students.

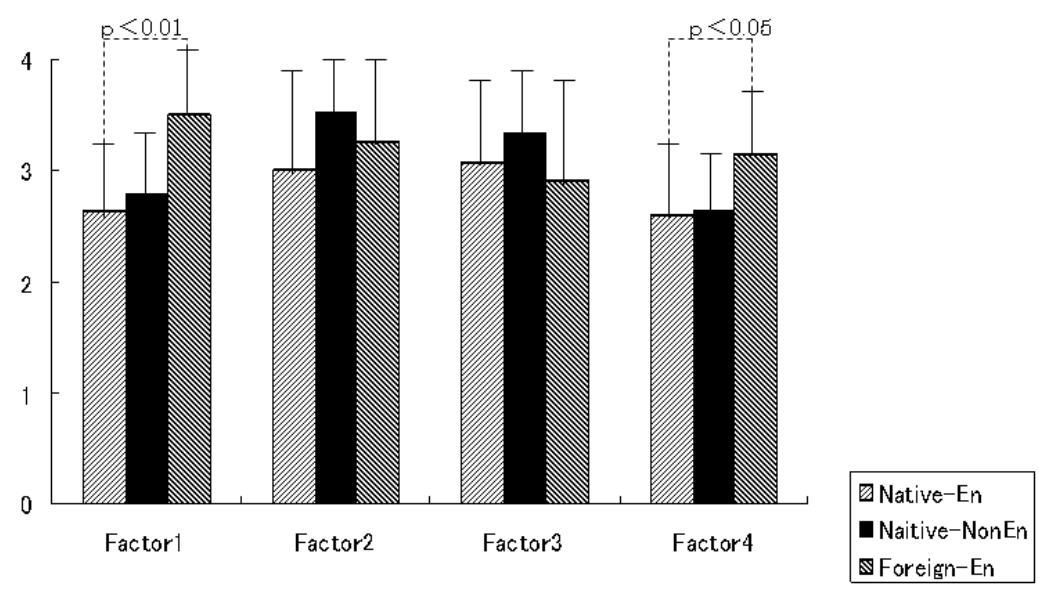

Figure 6: Comparison of Average Scores

\section{DISCUSSION}

Our proposed system has functions that lead students to learn both the traditional and original features typical to academic writing, and selects relevant tactics to activate students' comprehension of textual and graphical information.

Concerning the first research question, "Are there any differences between engineering and non-engineering majors with regard to their preference for multimedia e-Learning?" results indicate that there was no significant difference between engineering and non-engineering students with regard to all four factors.

This indicates that the two groups of Japanese students have very similar patterns for all four factors. Among four factors, the results of Fig.6 show that the average scores of Factor 2 and Factor 3 are higher than those of Factor 1 and Factor 4.

With regard to the second research question, "Are there any differences between foreign and native Japanese students in engineering with regard to their preference for multimedia e-Learning?" there was no difference between foreign and Japanese students with regard to Factor 2 (Effectiveness of Auto Glossary) and Factor 3 (Positive Perception of Multimedia Effects). This is due to the fact both Japanese and foreign students have very similar patterns for Factor 2 and Factor 3. In other words, both native and foreign students 
positively evaluate the items with regard to auto glossary (Factor 2) and multimedia effects (Factor 3 ) in courseware.

On the other hand, the mean for foreign students was higher than that of native Japanese students for both Factor 1 (Positive reaction to e-Learning content) and Factor 4 (Positive Perception of Reading with Narration). Though foreign student responses on the survey indicate a strong preference for use in a multimedia-based approach, Japanese students did not show a strong preference in Factor 1 and Factor 4. It indicates that foreign students have a greater preference for use in multimedia learning environments, especially video clips and sounds files provided with textual information, than native Japanese learners. On the other hand Japanese students did not positively evaluate various tasks to promote understanding technical reading and streaming lectures in courseware.

No conclusive explanation can be given at this stage, but it is possible that e-Learning environments may lead foreign students to study reading comprehension and taking lectures for better preparation of academic life at colleges and universities.

We believe that a multimedia-based approach is effective and has the potential to provide attractive learning environments, which synthesize reading comprehension and taking lectures for various learners.

\section{CONCLUSION}

The results of the present study have relevance for instructional design for learners' diversity. The first implication derives from the fact that both native and foreign students positively evaluated the items with regard to auto glossary (Factor 2) and multimedia effects (Factor 3) in courseware. This suggests that auto glossary and streaming lectures are positively evaluated by both native and foreign students. Then, the contents' quality and difficulty should be carefully controlled with consideration for appropriate levels of both of users.

The second implication derives from the fact that the mean for foreign students was higher than that of native Japanese students for both Factor 1 (Positive reaction to e-Learning content) and Factor 4 (Positive Perception of Reading with Narration). Generally, foreign students evaluate e-Learning contents more positively than Japanese students. There was a gap between the two with regard to the function of Reading with Narration. Although this function was seen as effective for technical reading by foreign students, it was not by Japanese students.

The limitations of a single study that used only one content area, one text, and a limited number of participants cannot be ignored. Additional developmental research for e-Learning is required to more fully understand the strengths and limitations of this survey. We are developing a new reading e-Learning system (http:/www.elp.tuat.ac.jp), which includes more language tasks and multimedia resources on various areas. 


\section{FUTURE WORK}

We plan to incorporate both developmental and empirical approaches in our future studies. Since our system framework is, at present, still in its preliminary form, we are continuing to investigate how to implement the functions mentioned above. In order to prepare appropriate materials, we need to learn how multimedia effects are evaluated by the learner's language proficiency and background knowledge.

Another future research direction is to promote the cooperation between Japanese language teachers and professionals in specialized fields. Through this collaborative work, knowledge for designing technical literacy curricula will be discussed and shared for technological literacy education.

By use of Web-Based technologies, a faculty learning community is organized to share knowledge and improve teaching and learning. WebBased Teaching/Learning Platform, such as Moodle and WebCT, provide busy teachers with an opportunity to work with other teachers and exchange their ideas on strategic teaching and learning. Web-Based Teaching/ Learning Platform can be also used for instructional design databases in higher education.

\section{REFERENCES}

Colpaert, J. (2006): "Pedagogy-driven design for online language teaching and learning", CALICO Journal, 23, 177-497.

Dansuwan, S., et al. (2001): "Thai language learning system on the WWW using natural language processing and the evaluation", CALICO, 19, 6788.

Ercetin, G. (2003): “Exploring ESL learner's use of hypermedia reading glosses", CALICO Journal, 20, 261-283.

Foshay, W. R., Silber, K.H. \& Stelnicki. (2003): "Writing Training Materials that Work", San Francisco: Jossey-Bass/Pfeiffer.

Fukao, Y. (1994). "Teaching Japanese in reading comprehension class in technical literature", Journal of Japanese Language Teaching, Vol.82, 112.

Itoh, R. \& Hannon, C. (2002): "The effects of online quizzes on learning Japanese", CALICO Journal, 19, 551-561.

Kaji, A. (1983). "Teaching Japanese to Students of Chemistry", Journal of Japanese Language Teaching, Vol. 51, 49-52.

Kato, Y. \& Akiyama, M. (2006): "Development of E-learning contents for reading scientific and technical documents as subject matter of guidebook to research topic in TUAT for high school students", The Journal of Japanese Language Education Methods, 13(1), 38-39. 
Kato, Y. (2005): "Differences of criterion for evaluating Japanese reading support system between Japanese language teacher and foreign students" Journal of Multimedia Aided Education Research, 2(1), 175-187.

Kato, Y. (2006): "Teacher's collaboration for development of e-Learning contents for reading technological texts", Proceedings of the22nd annual conference of JSET, 803-804.

Kato, Y. et al. (2002): "A relevant learning framework for nonnative speakers: a proposal for integrating textual and graphical information in Japanese academic reading", Information and Systems in Education, 1, 70-79.

Konishi, H (1983). "Problems in instruction of primary science subjects in the foreign students' course", Journal of Japanese Language Teaching, Vol. 51, 27-36.

Nagata, N. (1996): "Computer vs. workbook instruction in second language acquisition", CALICO Journal, 14, 53-75.

Nagata, N. (1998): "Input vs. output practice in educational software for second language acquisition", Language Learning \& Technology (Online), 1, 23-40. Available: 1lt.msu.edu.

Obayashi, F. at al. (2002): "A study of learning support system for integrative study", Journal of Information Processing, 43(8), 2764-2773.

Rover, D.T. (2006): "The Academic Bookshelf: Teaching engineering to a wider audience", Journal of Engineering Education, 95, 347-349.

Shin J-e. \& Wastel, D. G. (2001): "A user-centered methodological framework for the design of hypermedia-based CALL systems", CALICO Journal, $18,517-538$.

Suzuki, K. (2002). Instructional design manual, Kyoto: Kitaoji.

Tsujii, J. (1983). "Experiences of teaching information sciences for Chinese students", Journal of Japanese Language Teaching", Vol. 51, pp.49-52.

Watts, N. (1997): "A learner-based design model for interactive multimedia language learning packages", System, 25, 1-8.

Yamamoto, K. (1995). "The acquisition of advanced Japanese reading ability for material science students at the MIT summer course", Journal of Japanese Language Teaching, Vol. 86, 190-203.

Note: This work has been partly supported by E-Learning Projects at TUAT : http://www.elp.tuat.ac.jp 